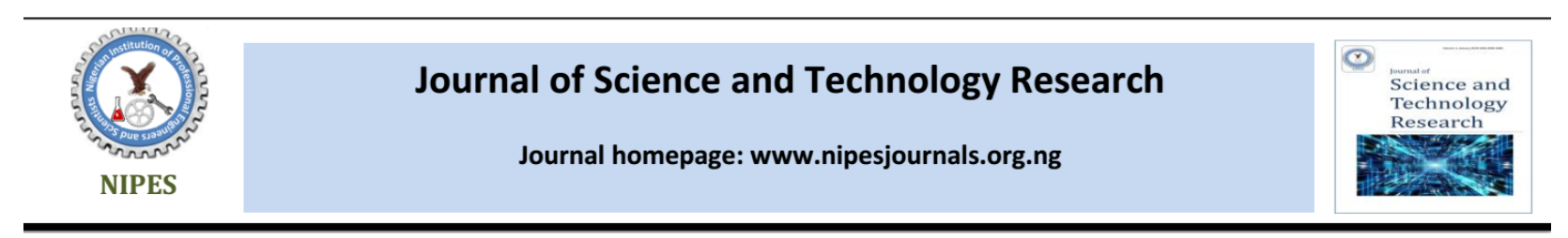

\title{
Multiplicative Cyclic Contraction Mappings Class and Best Proximity Point Theorems
}

\section{${ }^{1}$ Terrang, A.U, ${ }^{2}$ Akinwunmi, S.A, ${ }^{3}$ Oyewola, D.O and ${ }^{4}$ Bitrus, M.M}

$123 \& 4$ Department of Mathematics and Computer Science, Faculty of Science, Federal University of Kashere,P.M.B, 0182, Gombe E-mails:1 abterrang@ fukashere.edu.ng, ${ }^{2}$ sakinwunmi@fukashere.edu.ng, ${ }^{3}$ davidakaprof01@ yahoo.com and ${ }^{4}$ mohzo4real@gmail.com

\section{Article Info}

\section{Keywords:}

Contraction mapping, Collapse,

Height, Waist 2010 Mathematics

Subject Classification: 16W2, 10X2,

06F05 and $09 F 06$

Received 04 March 2020

Revised 02 April 2020

Accepted 09 April 2020

Available online 1 June 2020

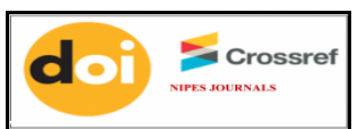

https://doi.org/10.37933/nipes/2.2.2020.7

\section{Abstract}

Let $A$ and $B$ be non-empty subset of a multiplicative metric space $(X, d)$ and $T: A \cup B \rightarrow A \cup B$ be a multiplicative $R$-cyclic contraction with respect to $\Psi$. Then there exists a sequence $\left\{x_{n}\right\}_{n \in \mathbb{N}} \subset A \cup B$ such that $\lim _{n \rightarrow \infty} d\left(x_{n}, x_{n+1}\right)=i n f_{n \in \mathbb{N}} d\left(x_{n}, x_{n+1}\right)=$ $d(A, B)$, then $\lim _{n \rightarrow \infty} d\left(x_{n}, x_{n+1}\right)=i n f_{n \in \mathbb{N}} d\left(x_{n}, x_{n+1}\right)=$

$\operatorname{dist}(A, B)$. This paper provides solutions to numerous problems in physics, optimization and economics, which can be reduced to finding a common best proximity point of some non-linear operator. We considered the application of cyclic contraction mapping on the multiplicative metric space then we obtain $\lim _{n \rightarrow \infty} d\left(x_{n}, x_{n+1}\right)=$ inf $f_{n \in \mathbb{N}} d\left(x_{n}, x_{n+1}\right)=\operatorname{dist}(A, B), d(A, B) \stackrel{n \rightarrow \infty}{\leq} d(v, T v) \leq d(A, B)$, $d(v, T v)=d(A, B), d(T x, T y) \leq(d(x, y))^{\Psi(d(x, y))}$. $d(A, B)^{1-\Psi(d(x, y))} \leq(\max \{d(x, y),[d(T x, x) \cdot d(T y, y)$. $\left.\min \{d(x, T y), d(y, T x)\}]^{\frac{1}{2}}\right)^{\varphi(d(x, y))} \cdot d(A, B)^{1-\varphi(d(x, y))}$ for all $x \in$ $A$ and $y \in B$.

https://nipesjournals.org.ng

ISSN-2682-5821/@ 2020 NIPES Pub.

All rights reserved.

\section{Introduction}

Best proximity point theorem was first established by [1], which is a concept that analyses the existence of an optimal solution; and is a natural generalization of Banach fixed point theorem. The concept of multiplicative metric spaces is another important result that was introduced by [2]. They defined multiplicative metric space in such a way that the additive triangular inequality is replaced by "multiplicative triangular inequality" $d(x, y) \leq d(x, z) \cdot d(z, y)$ for all $x, y, z \in X$. The concept of multiplicative contraction mappings and proved some fixed point theorems on such mappings in a complete multiplicative metric space was firstly introduced by [3]. Some unique fixed point theorems in the context of multiplicative metric spaces was proved by [4], their results extended some well-known results from the literature to multiplicative metric space. They discovered that some fixed point theorems can be deduced in multiplicative metric space by using the established result. They also, gave an appropriate example to illustrate their results. A common fixed point result of quasi-weak commutative mappings on a closed ball in the frame work of multiplicative metric spaces was presented by [5]. They provided a non-trivial example to support their results. They also, studied sufficient conditions for the existence of a common solution of multiplicative boundary value problem. 
A lot of researches were made on multiplicative metric space to prove results that hold on standard metric space of which is the best proximity points such as [1] whom established interesting best proximity point theorems for relatively non-expansive mapping. Later in 2012, [6] used R-function to establish best proximity point theorem in metric space. Moreover, [7] also introduce a new class of cyclic contraction mapping and considered the best proximity point theorem in the context of metric space.

The current article provides solutions to numerous problems in Physics, Optimization and Economics, which can be reduced to finding a common best proximity point of some non-linear operator. Our results can be used to solve problems in Non-Newtonian calculus if all the required conditions are satisfied. We considered the application of cyclic contraction mapping on the multiplicative metric space. We establish the best proximity point theorems for cyclic contraction mapping and generalized cyclic contraction mapping in multiplicative metric space and applied it on the best proximity point theorems.

Various authors have generalized Banach contraction principle in different spaces. The first analytic attempt at generalizing fixed point theorem to infinite dimensional spaces was made by [8]. They were able to show that a continuous operator defined from a compact, convex subset of $C^{m}[0,1]$ into itself has a fixed point. This result was then applied in solving certain differential and integral equations. But few authors have worked on multiplicative metric spaces. Such as [3], [4], [9]. Specifically, [3] introduced the concept of multiplicative contraction mappings and proved some fixed point theorems of such mappings on a complete multiplicative metric space. The weak commutative mappings on a multiplicative metric space was studied by $[4,9]$ generating some unique fixed point theorems in the set-up of multiplicative metric space. For further detail about multiplicative metric space and concept, we refer the reader to [3], [4] [10] and [11]. The concept of the best approximation theorems which is a concept that explores the existence of an approximate solution was introduced by [12], despite the fact that there is no known constructive technique for determining a fixed point of $\mathrm{T}$, the Schauder-Tychonov fixed point theorem is extremely important in the proofs of many existence theorems of differential equations. We have observed that generalization of the Browder fixed point theorem to infinite dimensional spaces have involved additional condition on its domain.

In some theorems, we may assume that the closed unit ball is compact and convex. Furthermore, since the compactness assumption of some theorems is often difficult to obtain in applications, considerable research has been done concerning weaker conditions for the domain which guarantee the existence of fixed point. Some common fixed point theorems for different mappings on 2-metric space was studied by [13] and [14] which was used by [15] to derived some common fixed point theorems related to weak commutative mappings on a complete metric space. Furthermore, [16] studied various fixed point results on the class of generalized metric spaces. Some fixed point results related to monotone operators in the setting of metric space equipped with partial order using a weak generalized contraction typed mapping was discussed by [17] which led to the characterization of metric completeness by generalized Banach contraction mappings in complete Hausdorff generalized metric spaces by [18].

The extensive application potential of fixed point theory in various fields in several generalizations of the metric spaces, rectangular metric spaces, D-metric spaces, and G-metric spaces. Perhaps one of the most interesting generalizations is the G-metric space which was introduced by [16] that drawn the attention of mathematicians and became a very popular subject especially from the point of view of fixed point theory. Cyclic maps and in particular the fixed points of cyclic maps have been a subject of growing interest recently. The main number of studies regarding fixed points is 
weakening the contractive conditions on the map under consideration. A map $T: X \rightarrow X$ on a metric space $(X, d)$ is called a weak $\varphi$-contraction if there exists a strictly increasing function $\varphi:[0, \infty) \rightarrow$ $[0, \infty)$ with $\varphi(0)=0$ such that $d(T x, T y) \leq d(x, y)-\varphi(d(x, y))$,

For all $x, y \in X$. These types of contractions have also been a subject of extensive research.

\section{Basic Preliminaries}

In this section, we present some basic definitions and results concerning the cyclic contraction mapping and best proximity point theorems.

Definition 2.1 [Metric Space]: Let $X$ be a non-empty set. A function $d: X^{2} \rightarrow R^{+}$is said to be a metric on $\mathrm{X}$ if for any $x, y, z \in X$, the following condition hold: $\left(m_{1}\right) d(x, y) \geq 0,\left(m_{2}\right) d(x, y)=$ 0 iff $x=y,\left(m_{3}\right) d(x, y)=d(y, x)$ and $\left(m_{4}\right) d(x, y) \leq d(x, z)+d(z, y)$.

Definition 2.2 [Multiplicative Metric Space]: Let $X$ be non-empty set. A function $d: X^{2} \rightarrow R^{+}$is said to be multiplicative metric on $\mathrm{X}$ if for any $x, y, z \in X$, the following condition hold: $\left(d_{1}\right) d(x, y) \geq 1$ and $d(x, y)=1$ iff $x=y,\left(d_{2}\right) d(x, y)=d(y, x)$ and $\left(d_{3}\right) d(x, y) \leq d(x, z)$. $d(z, y)$.Then pair $(X, d)$ is called a Multiplicative Metric Space for all $x, y, z \in X$.

Definition 2.3 [Contraction Mapping]: Let $(X, d)$ be metric space. A mapping : $X \rightarrow X$ is called contraction if there exists a real constant $\lambda \in[0,1]$ such that $d(f(x), f(y)) \leq \lambda d(x, y)$ for all $x, y \in$ $X$.

Definition 2.4 [Multiplicative Contraction]: Let $X$ be a multiplicative metric space. A mapping $T: X \rightarrow X$ is said to be multiplicative contractive if there exist $\lambda \in[0,1)$ such that $d(T x, T y) \leq$ $d(x, y)^{\lambda}$, for all $x, y \in X$.

Definition 2.5 [Cyclic Contraction Mapping]: Let $A$ and $B$ be non-empty subset of a metric space $(X, d)$, a cyclic map $T: A \cup B \rightarrow A \cup B$ is called a cyclic contraction mapping, if $\exists k \in[0,1)$ such that $d(T x, T y) \leq k d(x, y)+(k-1) \operatorname{dist}(A, B)$, for all $x \in A$ and $y \in B$.

Definition 2.6 [K-Cyclic Mapping]: Two mappings $\mathrm{T}: \mathrm{A} \rightarrow \mathrm{B}$ and $\mathrm{S}: \mathrm{B} \rightarrow \mathrm{A}$ is said to form a $\mathrm{K}$ Cyclic mapping between $\mathrm{A}$ and $\mathrm{B}$ if there exists a non-negative real number $\lambda<\frac{1}{2}$ such that $d(T x, S y)=\lambda[d(x, T x)+d(y, S y)]+(1-2 \lambda) \operatorname{dist}(A, B)$ for all $x \in A$ and $y \in B$.

Definition 2.7 [C-Cyclic Mapping]: Two mappings $\mathrm{T}: \mathrm{A} \rightarrow \mathrm{B}$ and $\mathrm{S}: \mathrm{B} \rightarrow \mathrm{A}$ is said to form a $\mathrm{C}$ Cyclic mapping between $\mathrm{A}$ and $\mathrm{B}$ if there exists a non-negative real number $\lambda<\frac{1}{2}$ such that $d(T x, S y)=\lambda[d(x, S y)+d(y, T x)]+(1-2 \lambda) \operatorname{dist}(A, B)$ for all $x \in A$ and $y \in B$.

Definition 2.8 [R-Cyclic Contraction Mapping]: Let A and B be non-empty subsets of a metric space $(X, d)$. if a map $T: A \cup B \rightarrow A \cup B$ satisfies $\left(M T_{1}\right) T(A) C B$ and $T(B) C A,\left(M T_{2}\right) \exists$ an $R$ function $\varphi:[0, \infty) \rightarrow[0,1)$ such that $d(T x, T y) \leq \varphi(d(x, y)) d(x, y)+(1-\varphi(d(x, y))$ then dist (A,B), for any $x \in A$ and $y \in B$.Then T is called $R$-Cyclic contraction with respect to $\varphi$ on $A \cup B$.

Definition 2.9 [Generalized R-Cyclic Contraction Mapping]: Let A and B be non-empty subsets of a metric space $(X, d)$. A cyclic map T: $\mathrm{A} \cup B \rightarrow A \cup B$ is called generalized R-cyclic contraction mapping if there exists R-function $\varphi$ such that $\quad d(T x, T y) \leq$ $\varphi d((x, y)) \max \left\{d(x, y), \frac{1}{2}[d(T x, x)+d(T y, y)+\min \{d(x, T y), d(y, T x)\}]\right\}+(1-$ $\varphi(d(x, y))) \operatorname{dist}(A, B)$ for all $x \in$ Aandy $\in B$. 
Definition 2.10 [Weak $M T-K$ Condition]: Let A and B be non-empty subsets of a metric space $(X, d)$ and $T: A \rightarrow B$ and $S: B \rightarrow A$ be maps. We say that the pair of maps $\mathrm{T}$ and $\mathrm{S}$ satisfy weak $M T$ $K$ condition if there exists an MT-function $\varphi:[0, \infty) \rightarrow[0,1)$ such that $d(T x, S y)=$ $\frac{1}{2} \varphi(d(x, y))[d(x, T x)+d(y, S y)]+(1-\varphi d(x, y)) \operatorname{dist}(A, B)$ for all $x \in$ Aandy $\in B$.

Definition 2.11 [Weak $M T$ - $C$ Condition]: Let A and B be non-empty subsets of a metric space $(X, d)$ and $T: A \rightarrow B$ and $S: B \rightarrow A$ be maps. We say that the pair of maps T and $S$ satisfy weak $M T-C$ condition if there exists an MT-function $\varphi:[0, \infty) \rightarrow[0,1)$ such that $d(T x, S y)=$ $\frac{1}{2} \varphi(d(x, y))[d(x, S y)+d(y, T x)]+(1-\varphi d(x, y)) \operatorname{dist}(A, B)$ for all $x \in$ Aandy $\in B$.

Definition 2.12 [MT-KC Condition]: Let A and B be non-empty subsets of a metric space $(X, d)$ and $T: A \rightarrow B$ and $S: B \rightarrow A$ be two maps. The pair of maps $\mathrm{T}$ and $\mathrm{S}$ is said to satisfy weak $M T-K C$ condition if there exists a pair of function, $\omega:[0, \infty) \rightarrow[0,1)$ satisfy the weak $M T-K C$ condition such that $d(T x, S y)=\alpha \varphi(d(x, y))[d(x, T x)+d(y, S y)]+\beta \omega(d(x, y))(d(x, S y)+d(y, T x))(1-$ $2(1-2 \alpha \varphi d(x, y)-2 \beta \omega(d(x, y))) \operatorname{dist}(A, B)$ for all $x \in$ Aandy $\in$ and $\alpha \beta \leq \frac{1}{2}$

Definition 2.13 [Weak $\varphi$-contraction]: A map $T: X \rightarrow X$ on a metric space $(X, d)$ is called a weak $\varphi$-contraction if there exists a strictly increasing function $\varphi:[0, \infty) \rightarrow[0, \infty)$ with $\varphi(0)=0$ such that $d(T x, T y) \leq d(x, y)-\varphi(d(x, y))$, for all $x, y \in X$.

Definition 2.14 [Best Proximity Point of a function]: Let A and B be nonempty closed and convex subsets of a complete metric space $(X, d)$ and let $T: A \cup B \rightarrow A \cup B$ be cyclic. Assume that, for all $x \in A$ and $y \in B$ then $d(x, T x)=d(A, B)$. such that $\alpha \in(0,1)$ then $d(A, B)=\inf \{d(x, y), x \in$ $A, y \in B\}$. for $x_{0} \in A$, define $x_{n+1}=T x_{n}$ for each $n \geq 0$. Then, there exists unique $x \in$ $A$ such that $x_{2 n} \rightarrow x$ and $d(x, T x)=d(A, B)$. hence, $x$ is called best proximity point of a function $\mathrm{T}$.

Definition 2.15 [Generalized Metric (G-metric on X)]: Let $\mathrm{X}$ be a nonempty set, $G: X \times X \times X \rightarrow$ $R^{+}$be a function satisfying the following properties: $\mathrm{G} 1: G(x, y, z)=0$ if $x=y=z, \mathrm{G} 2: 0<$ $G(x, x, y)$ for all $x, y \in X$ with $x \neq y, \mathrm{G} 3: G(x, x, y) \leq G(x, y, z)$ for all $x, y, z \in X$ with $y \neq$ $z, \mathrm{G} 4: G(x, y, z)=G(x, z, y)=G(y, z, x)=\cdots$ (symmetric in all three variables), G5: $G(x, y, z) \leq$ $G(x, a, a)+G(a, y, z)$ forall $x, y, z, a \in X$ (rectangle inequality), then the function $\mathrm{G}$ is called generalized metric, or, more specifically, G-metric on $\mathrm{X}$, denoted by $(X, G)$ :G-metric space.

Definition 2.16 [Multiplicative Cyclic Contraction]: Let $\mathrm{A}$ and $\mathrm{B}$ be non-empty subset of a multiplicative metric space $(X, d)$. A cyclic map $T: A \cup B \rightarrow A \cup B$ is called multiplicative cyclic contraction if $\exists \lambda \in[0,1)$ such that $d(T x, T y) \leq d(x, y)^{\lambda} \cdot d(A, B)^{1-\lambda}$, for all $x \in A$ and $y \in B$.

Definition 2.17 [C-Cyclic Mappings]: Two mappings $\mathrm{T}: \mathrm{A} \rightarrow \mathrm{B}$ and $\mathrm{S}: \mathrm{B} \rightarrow \mathrm{A}$ is said to form a CCyclic mapping between $\mathrm{A}$ and $\mathrm{B}$ if $\exists$ a non-negative real number $\lambda<\frac{1}{2}$ such that $d(T x, S y)=$ $\lambda[d(x, S y)+d(y, T x)]+(1-2 \lambda) \operatorname{dist}(A, B)$ for all $x \in A$ and $y \in B$.

Definition 2.18 [Weak $M T$ - $K$ Condition]: Let A and B be non-empty subsets of a metric space $(X, d)$ and $T: A \rightarrow B$ and $S: B \rightarrow A$ be maps, then $\mathrm{T}$ and $\mathrm{S}$ satisfy weak $M T-K$ condition if there exists an $M T$-function $\varphi:[0, \infty) \rightarrow[0,1)$ such that $d(T x, S y)=\frac{1}{2} \varphi(d(x, y))[d(x, T x)+$ $d(y, S y)]+(1-\varphi d(x, y)) \operatorname{dist}(A, B)$ for all $x \in A$ and $y \in B$, and $T: A \rightarrow B$ and $S: B \rightarrow A$ then $\mathrm{T}$ and $S$ satisfy weak $M T-C$ condition if there exists $M T$-function $\varphi:[0, \infty) \rightarrow$ 
$[0,1)$ such that $d(T x, S y)=\frac{1}{2} \varphi(d(x, y))[d(x, S y)+d(y, T x)]+(1-\varphi d(x, y)) \operatorname{dist}(A, B)$ for all $x \in$ Aandy $\in B$.

\section{Multiplicative Cyclic Contraction Mappings Class and Best Proximity Point Theorems}

In this section, we introduce two new classes of multiplicative contraction mappings; multiplicative cyclic contraction and multiplicative R-cyclic contraction mappings, and establish best proximity point theorems with these mappings within the frameworks of multiplicative metric space. The method adopted in this research was through consulting necessary and relevant literatures mentioned in section two.

Theorem 3.1: Let $\mathrm{A}$ and $\mathrm{B}$ be non-empty subset of a multiplicative metric space $(X, d)$ and $T: A \cup$ $B \rightarrow A \cup B$ be a multiplicative cyclic contraction. For $x_{1} \in A$ arbitrary chosen, define an iterative sequence $\left\{x_{n}\right\}_{n \in \mathbb{N}}$ by $x_{n+1}=T x_{n}$ then,

$\lim _{n \rightarrow \infty} d\left(x_{n}, x_{n+1}\right)=i n f_{n \in \mathbb{N}} d\left(x_{n}, x_{n+1}\right)=d(A, B)$

Proof: First we show that the sequence $\left\{d\left(x_{n}, x_{n+1}\right)\right\}$ is non-increasing. Now, let us fix $n \in \mathbb{N}$; since $\mathrm{T}$ is a multiplicative cyclic contraction mapping, we see that

$$
\begin{gathered}
d\left(x_{n+2}, x_{n+1}\right)=d\left(T x_{n+1}, T x_{n}\right) \\
\leq d\left(x_{n+1}, x_{n}\right)^{\lambda} \cdot d(A, B)^{1-\lambda} \\
\leq d\left(x_{n+1}, x_{n}\right)^{\lambda} \cdot d\left(x_{n+1}, x_{n}\right)^{1-\lambda} \\
\lim _{n \rightarrow \infty} d\left(x_{n}, x_{n+1}\right)=\inf _{n \in \mathrm{N}} d\left(x_{n}, x_{n+1}\right)=d(A, B)=1=\frac{d\left(x_{n+1}, x_{n}\right)^{\lambda} \cdot d\left(x_{n+1}, x_{n}\right)}{d\left(x_{n+1}, x_{n}\right)^{\lambda}} \\
=d\left(x_{n+1}, x_{n}\right) .
\end{gathered}
$$

From (3.4) we need to show that the sequence $\left\{d\left(x_{n}, x_{n+1}\right)\right\}$ is non-increasing. If there exists $j \in$ $\mathbb{N}$ such that $x_{j}=x_{j+1} \in A \cap B$. Then by definition $T x_{j}=x_{j+1}=x_{j}$; also $x_{j+2}=T x_{j+1}=$ $T\left(T x_{j}\right)=T x_{j}=x_{j}$. So $x_{j}=x_{j+1}=x_{j+2}=\cdots$ therefore the $\lim _{n \rightarrow \infty} d\left(x_{n}, x_{n+1}\right)=1$.

Then, $\lim _{n \rightarrow \infty} d\left(x_{n}, x_{n+1}\right)=i n f_{n \in \mathbb{N}} d\left(x_{n}, x_{n+1}\right)=d(A, B)=1$

Similarly, we consider the case $x_{n+1} \neq x_{n}$ for all $n \in \mathbb{N}$. If $x_{1} \in A$, then by the cyclic nature of T, we have $x_{2 n-1} \in A$ and $x_{2 n} \in B$ for all $n \in \mathbb{N}$. Since

$$
\begin{aligned}
& \mathrm{d}\left(x_{2}, x_{3}\right)=d\left(T x_{1}, T x_{2}\right) \quad \leq d\left(x_{1}, x_{2}\right)^{\lambda} \cdot d(A, B)^{1-\lambda} \\
& d\left(x_{3}, x_{4}\right)=d\left(T x_{2}, T x_{3}\right) \quad \leq d\left(x_{2}, x_{3}\right)^{\lambda} \cdot d(A, B)^{1-\lambda} \\
& \quad \leq\left(d\left(x_{1}, x_{2}\right)^{\lambda} \cdot d(A, B)^{1-\lambda}\right)^{\lambda} \cdot \operatorname{dist}(A, B)^{1-\lambda} \\
& =d\left(x_{1}, x_{2}\right)^{\lambda^{2}} \cdot d(A, B)^{1-\lambda^{2}}
\end{aligned}
$$

and

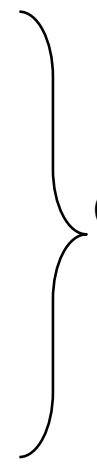




$$
\begin{aligned}
d\left(x_{4}, x_{5}\right)=d\left(T x_{3}, T x_{4}\right) \leq & d\left(x_{3}, x_{4}\right)^{\lambda} \cdot d(A, B)^{1-\lambda} \\
& \leq\left(d\left(x_{1}, x_{2}\right)^{\lambda^{2}} \cdot d(A, B)^{1-\lambda^{2}}\right)^{\lambda} \cdot \operatorname{dist}(A, B)^{1-\lambda} \\
= & d\left(x_{1}, x_{2}\right)^{\lambda^{3}} \cdot d(A, B)^{1-\lambda^{3}}
\end{aligned}
$$

hence we have $\operatorname{dist}(A, B) \leq d\left(x_{n+1}, x_{n+2}\right) \leq d\left(x_{1}, x_{2}\right)^{\lambda^{n}} \cdot d(A, B)^{1-\lambda^{n}}$

For $n \in \mathbb{N}$.Since $\lambda \in[0,1), \lim _{n \rightarrow \infty} \lambda^{n}=0$. The proof follows immediately from (6) and the nonincreasing nature of $\left\{d\left(x_{n}, x_{n+1}\right)\right\}$, therefore we obtain $\lim _{n \rightarrow \infty} d\left(x_{n}, x_{n+1}\right)=i n f_{n \in \mathbb{N}} d\left(x_{n}, x_{n+1}\right)=$ $\operatorname{dist}(A, B)$.

The following useful theorem of best proximity point theorem for multiplicative cyclic contractions follows immediately.

Theorem 3.2 Let A and B be non-empty subsets of a multiplicative metric space $(X, d)$ and $T: A \cup$ $B \rightarrow A \cup B$ be a multiplicative cyclic contraction map. Let $x_{1} \in A$ be chosen arbitrary and define an iterative sequence $\left\{x_{n}\right\}_{n \in \mathbb{N}}$ by $x_{n+1}=T x_{n}$. Suppose that $\left\{v \in A \cdot x_{2 n-1}\right\}$ has a multiplicative convergence in $\mathrm{A}$, then $\exists v \in A$ such that $d(v, T v)=d(A, B)$.

Proof: Let $T: A \cup B \rightarrow A \cup B$ be multiplicative cyclic contraction if there exists $\lambda \in$ $[0,1)$ such that $d(T x, T y) \leq d(x, y)^{\lambda} \cdot d(A, B)^{1-\lambda}$, for all $x \in A$ and $y \in B$. Since $\mathrm{T}$ is a cyclic map and $x_{1} \in A$ then $x_{2 n-1} \in A$ and $x_{2 n} \in B$ for all $n \in \mathbb{N}$, and

$\left\{x_{2 n_{k}-1}\right\}$ is a subsequence of $\left\{x_{2 n-1}\right\}$ multiplicatively converging to a point $v \in A$. Then by (multiplicative triangle inequality)

$d(A, B) \leq d\left(v, x_{2 n_{k}}\right) \leq d\left(v, x_{2 n_{k}-1}\right) \cdot d\left(x_{2 n_{k}-1}, x_{2 n_{k}} \quad\right.$ for $\quad$ all $\quad k \in \mathbb{N}$, and $\lim _{k \rightarrow \infty} d\left(v, x_{2 n_{k}-1}\right)=1$, we have $d(A, B) \leq d\left(v, x_{2 n_{k}}\right) \leq d\left(v, x_{2 n_{k}-1}\right) \cdot d\left(x_{2 n_{k}-1}, x_{2 n_{k}}\right)$

Taking limit as $k \rightarrow \infty$ we have $d(A, B) \leq \lim _{k \rightarrow \infty} d\left(v, x_{2 n_{k}}\right) \leq \lim _{k \rightarrow \infty} d\left(x_{2 n_{k}-1}, x_{2 n_{k}}\right)=d(A, B)$

$$
\begin{aligned}
& \text { then } \begin{array}{r}
\lim _{k \rightarrow \infty} d\left(v, x_{2 n_{k}}\right)= \\
=d(A, B) \text { if } d(A, B) \leq d\left(x_{2 n_{k}+1}, T v\right) \\
\left.\leq d\left(v, x_{2 n_{k}+1}, T v\right) \leq d\left(x_{2 n_{k}}, T v\right)^{\lambda} \cdot d(A, B)^{1-\lambda} \cdot x_{2 n_{k}}\right)^{1-\lambda} \\
\leq d\left(x_{2 n_{k}}, v\right)
\end{array}
\end{aligned}
$$

Therefore, $d(A, B) \leq d\left(x_{2 n_{k}+1}, T v\right) \leq d\left(x_{2 n_{k}}, v\right)$

taking limit as $k \rightarrow \infty$, we obtain

$$
d(A, B) \leq d(v, T v) \leq d(A, B),
$$

$d(v, T v)=d(A, B)$. 
Theorem 3.3: Let $\mathrm{A}$ and $\mathrm{B}$ be non-empty subset of a multiplicative metric space $(X, d)$ and $T: A \cup$ $B \rightarrow A \cup B$ be a multiplicative R-cyclic contraction with respect to $\Psi$. Then $\exists$ a sequence $\left\{x_{n}\right\}_{n \in \mathbb{N}} \subset$ $A \cup B$ such that

$\lim _{n \rightarrow \infty} d\left(x_{n}, x_{n+1}\right)=i n f_{n \in \mathbb{N}} d\left(x_{n}, x_{n+1}\right)=d(A, B)$.

\section{Proof:}

Let $x_{1} \in A$ be given. Define an iterative sequence $\left\{x_{n}\right\}_{n \in \mathbb{N}}$ by $x_{n+1}=T x_{n}$ for $n \in \mathbb{N}$, clearly $d(A, B) \leq d\left(x_{n}, x_{n+1}\right)$ for all $n \in \mathbb{N}$.

If there exists $j \in \mathbb{N}$ such that $x_{j}=x_{j+1} \in A \cap B$, then by definition $T x_{j}=x_{j+1}=x_{j}$. Also $x_{j+2}=$ $T x_{j+1}=T\left(T x_{j}\right)=T x_{j}=x_{j}$.So $x_{j}=x_{j+1}=x_{j+2}=\cdots$

Hence, $\lim _{n \rightarrow \infty} d\left(x_{n}, x_{n+1}\right)=1$.

Then $\lim _{n \rightarrow \infty} d\left(x_{n}, x_{n+1}\right)=i n f_{n \in \mathbb{N}} d\left(x_{n}, x_{n+1}\right)=d(A, B)=1 \quad$. It suffices to consider the case $x_{n+1} \neq x_{n}$ for all $n \in \mathbb{N}$. since the sequence $\left\{d\left(x_{n}, x_{n+1}\right)\right\}$ is non-increasing in $(1, \infty)$, then $t_{1}=$ $\lim _{n \rightarrow \infty} d\left(x_{n}, x_{n+1}\right)=i n f_{n \in \mathbb{N}} d\left(x_{n}, x_{n+1}\right) \geq 1$. Since $\varphi$ is an R-function we have, $0 \leq$ $\sup _{n \in \mathbb{N}} \varphi\left(d\left(x_{n}, x_{n+1}\right)\right)<1$.

Suppose $\lambda:=\sup _{n \in \mathbb{N}} \varphi\left(d\left(x_{n}, x_{n+1}\right)\right)$, then $0 \leq \varphi\left(d\left(x_{n}, x_{n+1}\right)\right) \leq \lambda<1$ for all $n \in \mathbb{N}$. If $x_{1} \in A$, then by the cyclic nature of $\mathrm{T}$, we have $x_{2 n-1} \in A$ and $x_{2 n} \in B$ for all $n \in \mathbb{N}$. Since $\mathrm{T}$ is a multiplicative cyclic R-contraction, we have $\quad d\left(x_{2}, x_{3}\right)=d\left(T x_{1}, T x_{2}\right)$

$$
\begin{aligned}
& \leq d\left(x_{1}, x_{2}\right)^{\Psi d\left(x_{1}, x_{2}\right)} \cdot d(A, B)^{1-\Psi d\left(x_{1}, x_{2}\right)} \\
& \leq d\left(x_{1}, x_{2}\right)^{\lambda} \cdot d(A, B) \text { and } d\left(x_{3}, x_{4}\right)=d\left(T x_{2}, T x_{3}\right) \\
& \leq d\left(x_{2}, x_{3}\right)^{\Psi d\left(x_{2}, x_{3}\right)} \cdot d(A, B)^{1-\Psi d\left(x_{2}, x_{3}\right)} \\
& \leq\left(d\left(x_{1}, x_{2}\right)^{\lambda} \cdot d(A, B)\right)^{\Psi d\left(x_{2}, x_{3}\right)} \cdot d(A, B)^{1-\Psi d\left(x_{2}, x_{3}\right)} \\
& =d\left(x_{1}, x_{2}\right)^{\lambda^{2}} \cdot d(A, B) \text { also, } d\left(x_{4}, x_{5}\right)=d\left(T x_{3}, T x_{4}\right) \\
& \leq d\left(x_{3}, x_{4}\right)^{\Psi d\left(x_{3}, x_{4}\right)} \cdot d(A, B)^{1-\Psi d\left(x_{3}, x_{4}\right)} \\
& \leq\left(d\left(x_{1}, x_{2}\right)^{\lambda^{2}} \cdot d(A, B)\right)^{\Psi d\left(x_{3}, x_{4}\right)} \cdot d(A, B)^{1-\Psi d\left(x_{3}, x_{4}\right)} \\
& =d\left(x_{1}, x_{2}\right)^{\lambda^{3}} \cdot d(A, B)
\end{aligned}
$$

Hence, we obtained $d(A, B) \leq d\left(x_{n+1}, x_{n+2}\right) \leq d\left(x_{1}, x_{2}\right)^{\lambda^{n}} \cdot d(A, B)$

For $n \in \mathbb{N}$. Since $\lambda \in[0,1), \lim _{n \rightarrow \infty} \lambda^{n}=0$. The non-increasing nature of $\left\{d\left(x_{n}, x_{n+1}\right)\right\}$, we obtain

$\lim _{n \rightarrow \infty} d\left(x_{n}, x_{n+1}\right)=i n f_{n \in \mathbb{N}} d\left(x_{n}, x_{n+1}\right)=\operatorname{dist}(A, B)$.

The existence theorem for a class of cyclic mappings follows immediately 
Theorem 3.4: Let $\mathrm{A}$ and $\mathrm{B}$ be non-empty subsets of a multiplicative metric space $(X, d)$ and $T: A \cup$ $B \rightarrow A \cup B$ be a multiplicative R-cyclic contraction. Let $x_{1} \in A$ be given. Define an iterative sequence $\left\{x_{n}\right\}_{n \in \mathbb{N}}$ by $x_{n+1}=T x_{n}$ for $n \in \mathbb{N}$. suppose further that $\left\{x_{2 n-1}\right\}$ has a multiplicative convergence subsequence in $\mathrm{A}$, then there exist $x \in A$ such that $d(x, T v)=d(A, B)$.

Proof: Let $\left\{x_{2 n_{k}-1}\right\}$ be a subsequence of $\left\{x_{2 n_{k}-1}\right\}$ such that $x_{2 n_{k}-1} \rightarrow x$ as $k \rightarrow \infty$. we observe that, $\quad d(A, B) \leq d\left(x, x_{2 n_{k}}\right) \leq d\left(x, x_{2 n_{k}-1}\right) \cdot d\left(x_{2 n_{k}-1}, x_{2 n_{k}}\right) \quad$ for $\quad$ all $k \in \mathbb{N}$, since $\lim _{k \rightarrow \infty} d\left(x, x_{2 n_{k}-1}\right)=1$, and

$$
d(A, B) \leq d\left(x, x_{2 n_{k}}\right) \leq d\left(x, x_{2 n_{k}-1}\right) \cdot d\left(x_{2 n_{k}-1}, x_{2 n_{k}}\right)
$$

Taking limit as $k \rightarrow \infty$ we have

$d(A, B) \leq \lim _{k \rightarrow \infty} d\left(x, x_{2 n_{k}}\right) \leq \lim _{k \rightarrow \infty} d\left(x_{2 n_{k}-1}, x_{2 n_{k}}\right)=d(A, B)$

Hence, $\lim _{k \rightarrow \infty} d\left(x, x_{2 n_{k}}\right)=d(A, B)$.

Then $d(A, B) \leq d\left(x_{2 n_{k}+1}, T x\right)=d\left(x_{2 n_{k}}, T x\right)$

$$
\begin{aligned}
& \leq d\left(x_{2 n_{k}}, x\right)^{\varphi\left(d\left(x_{2 n_{k}}, x\right)\right)} \cdot d(A, B)^{1-\varphi\left(d\left(x_{2 n_{k}}, x\right)\right)} \\
& \leq d\left(x_{2 n_{k}}, x\right)^{\varphi\left(d\left(x_{2 n_{k}}, x\right)\right)} \cdot d\left(x_{2 n_{k}}, x\right)^{1-\varphi\left(d\left(x_{2 n_{k}}, x\right)\right)} \\
& \quad \leq d\left(x_{2 n_{k}}, x\right)
\end{aligned}
$$

Therefore,$d(A, B) \leq d(x, T x) \leq d(A, B)$. then $d(x, T x)=d(A, B)$. which complete the proof (4).

Theorem 3.5: Let A and B be non-empty subset of a multiplicative metric space $(X, d)$ and $T: A \cup$ $B \rightarrow A \cup B$ be generalized multiplicative R-cyclic contraction. For each $x_{1} \in A$ define an iterative sequence $\left\{x_{n}\right\}_{n \in \mathbb{N}}$ by $x_{n+1}=T x_{n}$, for $n \in \mathbb{N}$. Then, $\lim _{n \rightarrow \infty} d\left(x_{n}, x_{n+1}\right)=i n f_{n \in \mathbb{N}} d\left(x_{n}, x_{n+1}\right)=$ $d(A, B)$.

Proof: We need to show that $\left\{d\left(x_{n}, x_{n+1}\right)\right\}$ is a non-increasing sequence. If $n \in \mathbb{N}$ is fixed and T is a generalized multiplicative R-cyclic contraction mapping, then $d\left(x_{n+2}, x_{n+1}\right)=d\left(T x_{n+1}, T x_{n}\right)$

$$
\begin{aligned}
& \leq\left(\operatorname { m a x } \left\{d\left(x_{n+1}, x_{n}\right),\left[d\left(T x_{n+1}, x_{n+1}\right) \cdot d\left(T x_{n}, x_{n}\right)\right\}\right.\right. \\
& \left.\left.\cdot \min \left\{d\left(x_{n+1}, T x_{n}\right), d\left(x_{n}, T x_{n+1}\right)\right\}\right]^{\frac{1}{2}}\right)^{\varphi\left(d\left(x_{n+1}, x_{n}\right)\right)} \cdot d(A, B)^{1-\varphi\left(d\left(x_{n+1}, x_{n}\right)\right)} \\
& \leq\left(\operatorname { m a x } \left\{d\left(x_{n+1}, x_{n}\right),\left[d\left(x_{n+2}, x_{n+1}\right) \cdot d\left(x_{n+1}, x_{n}\right)\right\}\right.\right. \\
& \left.\left.\cdot \min \left\{d\left(x_{n+1}, x_{n+1}\right), d\left(x_{n}, x_{n+2}\right)\right\}\right]^{\frac{1}{2}}\right)^{\varphi\left(d\left(x_{n+1}, x_{n}\right)\right)} \cdot d(A, B)^{1-\varphi\left(d\left(x_{n+1}, x_{n}\right)\right)} \\
& \leq\left(\max \left\{d\left(x_{n+1}, x_{n}\right),\left[d\left(x_{n+2}, x_{n+1}\right) \cdot d\left(x_{n+1}, x_{n}\right)\right\} \cdot d\left(x_{n+1}, x_{n+1}\right)\right]^{\frac{1}{2}}\right)^{\varphi\left(d\left(x_{n+1}, x_{n}\right)\right)} \\
& \cdot d(A, B)^{1-\varphi\left(d\left(x_{n+1}, x_{n}\right)\right)} \\
& \leq\left(\max \left\{d\left(x_{n+1}, x_{n}\right),\left[d\left(x_{n+2}, x_{n+1}\right) \cdot d\left(x_{n+1}, x_{n}\right)\right\}\right]^{\frac{1}{2}}\right)^{\varphi\left(d\left(x_{n+1}, x_{n}\right)\right)} \cdot d(A, B)^{1-\varphi\left(d\left(x_{n+1}, x_{n}\right)\right)}
\end{aligned}
$$


Suppose

$$
\left[d\left(x_{n+2}, x_{n+1}\right) \cdot d\left(x_{n+1}, x_{n}\right)\right]^{\frac{1}{2}}=\left(\operatorname { m a x } \left\{d\left(x_{n+1}, x_{n}\right),\left[d\left(x_{n+2}, x_{n+1}\right) \cdot\right.\right.\right.
$$

$\left.\left.\left.d\left(x_{n+1}, x_{n}\right)\right]^{\frac{1}{2}}\right\}\right)^{\varphi\left(d\left(x_{n+1}, x_{n}\right)\right)} \cdot d(A, B)^{1-\varphi\left(d\left(x_{n+1}, x_{n}\right)\right)}$, we see that, $d\left(x_{n+1}, x_{n}\right)^{\frac{1}{2}}<d\left(x_{n+2}, x_{n+1}\right)^{\frac{1}{2}}$ then $d\left(x_{n+1}, x_{n}\right)<d\left(x_{n+2}, x_{n+1}\right)$.

Implies $d\left(x_{n+2}, x_{n+1}\right)$

$$
\begin{gathered}
\left.\leq\left(\left[d\left(x_{n+2}, x_{n+1}\right) \cdot d\left(x_{n+1}, x_{n}\right)\right]^{\frac{1}{2}}\right\}\right)^{\varphi\left(d\left(x_{n+1}, x_{n}\right)\right)} \cdot d(A, B)^{1-\varphi\left(d\left(x_{n+1}, x_{n}\right)\right)}, \\
\left.\leq\left(\left[d\left(x_{n+2}, x_{n+1}\right) \cdot d\left(x_{n+1}, x_{n}\right)\right]^{\frac{1}{2}}\right\}\right)^{\varphi\left(d\left(x_{n+1}, x_{n}\right)\right)} \cdot d(A, B)^{1-\varphi\left(d\left(x_{n+1}, x_{n}\right)\right)} \\
=\left[d\left(x_{n+2}, x_{n+1}\right)^{2}\right]^{\frac{1}{2} \varphi\left(d\left(x_{n+1}, x_{n}\right)\right)} \cdot d(A, B)^{1-\varphi\left(d\left(x_{n+1}, x_{n}\right)\right)} \\
=d\left(x_{n+2}, x_{n+1}\right)^{\varphi\left(d\left(x_{n+1}, x_{n}\right)\right)} \cdot d(A, B)^{1-\varphi\left(d\left(x_{n+1}, x_{n}\right)\right)} \\
\leq d\left(x_{n+2}, x_{n+1}\right)^{\varphi\left(d\left(x_{n+1}, x_{n}\right)\right)} \cdot d\left(x_{n+2}, x_{n+1}\right)^{1-\varphi\left(d\left(x_{n+1}, x_{n}\right)\right)} \\
=d\left(x_{n+2}, x_{n+1}\right)
\end{gathered}
$$

Suppose by contradiction. Then, $\left[d\left(x_{n+1}, x_{n}\right) \cdot d\left(x_{n+2}, x_{n+1}\right)\right]^{\frac{1}{2}}<d\left(x_{n+1}, x_{n}\right)$ implies $d\left(x_{n+1}, x_{n}\right)^{\frac{1}{2}} \geq d\left(x_{n+2}, x_{n+1}\right)^{\frac{1}{2}}$

Implies $d\left(x_{n+1}, x_{n}\right) \geq d\left(x_{n+2}, x_{n+1}\right)$, since $\left\{d\left(x_{n}, x_{n+1}\right)\right\}$ is non-increasing sequence then there exists $j \in \mathbb{N}$ such that $x_{j}=x_{j+1} \in A \cap B$, then by definition $T x_{j}=x_{j+1}=x_{j}$. Also $x_{j+2}=T x_{j+1}=$ $T\left(T x_{j}\right)=T x_{j}=x_{j}, x_{j}=x_{j+1}=x_{j+2}=\cdots$

Therefore, $\lim _{n \rightarrow \infty} d\left(x_{n}, x_{n+1}\right)=1$.

Then, $\lim _{n \rightarrow \infty} d\left(x_{n+1}, x_{n}\right)=i n f_{n \in \mathbb{N}} d\left(x_{n+1}, x_{n}\right)=d(A, B)=1$.

So it remains to consider the case $x_{n+1} \neq x_{n}$ for all $n \in \mathbb{N}$, since the sequence $\left\{d\left(x_{n}, x_{n+1}\right)\right\}$ is non-increasing and by the property of R-function we have $0 \leq \varphi\left(d\left(x_{n+1}, x_{n}\right)\right) \leq \lambda<1$ for all $n \in$ $\mathbb{N}$ where $\lambda:=\sup _{n \in \mathbb{N}} \varphi\left(d\left(x_{n+1}, x_{n}\right)\right)$. from $x_{1} \in A$, we have $x_{2 n-1} \in A$ and $x_{2 n} \in B$ for all $n \in$ $\mathbb{N}$, since $\mathrm{T}$ is a multiplicative cyclic $\mathrm{R}$-contraction, then $d\left(x_{2}, x_{3}\right)=d\left(T x_{1}, T x_{2}\right)$

$$
\begin{gathered}
\leq d\left(x_{1}, x_{2}\right)^{\varphi\left(d\left(x_{1}, x_{2}\right)\right)} \cdot d(A, B)^{1-\varphi\left(d\left(x_{1}, x_{2}\right)\right)} \\
\quad \leq d\left(x_{1}, x_{2}\right)^{\varphi\left(d\left(x_{1}, x_{2}\right)\right)} \cdot d(A, B) \\
\leq d\left(x_{1}, x_{2}\right)^{\lambda} \cdot d(A, B)
\end{gathered}
$$

then, $d\left(x_{3}, x_{4}\right)=d\left(T x_{2}, T x_{3}\right)$

$$
\leq d\left(x_{2}, x_{3}\right)^{\varphi\left(d\left(x_{2}, x_{3}\right)\right)} \cdot d(A, B)^{1-\varphi\left(d\left(x_{2}, x_{3}\right)\right)}
$$

$\leq\left(d\left(x_{1}, x_{2}\right)^{\lambda} \cdot d(A, B)\right)^{\varphi\left(d\left(x_{2}, x_{3}\right)\right)} \cdot d(A, B)^{1-\varphi\left(d\left(x_{2}, x_{3}\right)\right)}=d\left(x_{1}, x_{2}\right)^{\lambda^{2}} \cdot d(A, B)$.

similarly, $d\left(x_{4}, x_{5}\right)=d\left(T x_{3}, T x_{4}\right)$ 


$$
\leq d\left(x_{3}, x_{4}\right)^{\varphi\left(d\left(x_{3}, x_{4}\right)\right)} \cdot d(A, B)^{1-\varphi\left(d\left(x_{3}, x_{4}\right)\right)}
$$

$\leq\left(d\left(x_{1}, x_{2}\right)^{\lambda^{2}} \cdot d(A, B)\right)^{\varphi\left(d\left(x_{3}, x_{4}\right)\right)} \cdot d(A, B)^{1-\varphi\left(d\left(x_{3}, x_{4}\right)\right)} \quad=d\left(x_{1}, x_{2}\right)^{\lambda^{3}} \cdot d(A, B)$. Hence, $d(A, B) \leq d\left(x_{n+1}, x_{n+2}\right) \leq d\left(x_{1}, x_{2}\right)^{\lambda^{n}} \cdot d(A, B)$ for all $n \in \mathbb{N}$. Since $\lambda \in[0,1), \lim _{n \rightarrow \infty} \lambda^{n}=0$.by the non-increasing nature of $\left\{d\left(x_{n}, x_{n+1}\right)\right\}$, then $\lim _{n \rightarrow \infty} d\left(x_{n}, x_{n+1}\right)=i n f_{n \in \mathbb{N}} d\left(x_{n}, x_{n+1}\right)=d(A, B)$.

From the above theorem, we establish the following best proximity point theorem for generalized multiplicative R-cyclic contractions.

Theorem 3.6: Let A and B be non-empty subsets of a multiplicative metric space $(X, d)$ and $T: A \cup$ $B \rightarrow A \cup B$ be a generalized multiplicative cyclic R-contraction. Let $x_{1} \in A$ be given. Define an iterative sequence $\left\{x_{n}\right\}_{n \in \mathbb{N}}$ by $x_{n+1}=T x_{n}$ for $n \in \mathbb{N}$. Suppose further that $\left\{x_{2 n-1}\right\}$ has a multiplicative convergence subsequence in $\mathrm{A}$, then there exist $x \in A$ such that $d(x, T x)=$ $d(A, B)$.

Proof: Let $\left\{x_{2 n_{k}-1}\right\}$ be a subsequence of $\left\{x_{2 n_{k}-1}\right\}$ multiplicative converging to a point $x \in A$. Since, by multiplicative triangle inequality, we have

$d(A, B) \leq d\left(x, x_{2 n_{k}}\right) \leq d\left(x, x_{2 n_{k}-1}\right) \cdot d\left(x_{2 n_{k}-1}, x_{2 n_{k}}\right), \quad$ for $\quad$ all $\quad k \in \mathbb{N}, \quad$ and since $\lim _{k \rightarrow \infty} d\left(x, x_{2 n_{k}-1}\right)=1$, then

$$
d(A, B) \leq d\left(x, x_{2 n_{k}}\right) \leq d\left(x, x_{2 n_{k}-1}\right) \cdot d\left(x_{2 n_{k}-1}, x_{2 n_{k}}\right)
$$

Taking limit as $k \rightarrow \infty$ we have

$$
d(A, B) \leq \lim _{k \rightarrow \infty} d\left(x, x_{2 n_{k}}\right) \leq \lim _{k \rightarrow \infty} d\left(x_{2 n_{k}-1}, x_{2 n_{k}}\right)=d(A, B)
$$

Hence, $\lim _{k \rightarrow \infty} d\left(x, x_{2 n_{k}}\right)=d(A, B)$.

On the other hand, since $T$ is a generalized $R$-cyclic contraction mapping we have,

$$
\begin{aligned}
d(A, B) \leq d( & \left.T x, x_{2 n_{k}+1}\right) \\
\leq & \max \left\{d\left(x, x_{2 n_{k}}\right),\left[d(T x, x) \cdot d\left(x_{2 n_{k}+1}, x_{2 n_{k}}\right)\right.\right. \\
\cdot & \left.\left.\min \left\{d\left(x, x_{2 n_{k}+1},\right), d\left(x_{2 n_{k}+1}, T x\right)\right\}\right]^{\frac{1}{2}}\right\}
\end{aligned}
$$

Letting $k \rightarrow \infty$, we obtain $d(A, B) \leq d(T x, x)$

$$
\begin{gathered}
\leq \max \left\{d(A, B),[d(T x, x) \cdot d(A, B) \cdot \min \{d(x, x), d(x, T x)\}]^{\frac{1}{2}}\right\} \\
=\max \left\{d(A, B),[d(T x, x) \cdot d(A, B) \cdot d(x, x)]^{\frac{1}{2}}\right\} \\
=\max \left\{d(A, B),[d(T x, x) \cdot d(A, B)]^{\frac{1}{2}}\right\}
\end{gathered}
$$

Now we consider the following two cases:

Case I: If $\max \left\{d(A, B),[d(T x, x) \cdot d(A, B)]^{\frac{1}{2}}\right\}=d(A, B)$, then it implies that; 
A.U Terrang et al. / NIPES Journal of Science and Technology Research 2(2) 2020 pp. 78-89

$$
d(A, B) \leq d(T x, x) \leq d(A, B)
$$

which also implies, $d(A, B)=d(T x, x)$

Case II: If $\max \left\{d(A, B),[d(T x, x) \cdot d(A, B)]^{\frac{1}{2}}\right\}=[d(T x, x) \cdot d(A, B)]^{\frac{1}{2}}$. then

$$
\begin{gathered}
d(T x, x) \leq[d(T x, x) \cdot d(A, B)]^{\frac{1}{2}} \\
d(T x, x) \leq d(A, B)
\end{gathered}
$$

And it follows that $d(T x, x)=d(A, B)$. It is clear that every $R$-cyclic contraction is a generalized $R$-cyclic contraction. Indeed, if $T$ is $R$-cyclic contraction then

$$
d(T x, T y) \leq(d(x, y))^{\Psi(d(x, y))} \cdot d(A, B)^{1-\Psi(d(x, y))}
$$

$\leq\left(\max \left\{d(x, y),[d(T x, x) \cdot d(T y, y) \cdot \min \{d(x, T y), d(y, T x)\}]^{\frac{1}{2}}\right)^{\varphi(d(x, y))} \cdot d(A, B)^{1-\varphi(d(x, y))}\right.$ for all $x \in A$ and $y \in B$. (6).

\section{Conclusion and Recommendations}

In this research, cyclic contraction mappings were studied in Multiplicative Metric Spaces, and we obtained Best Proximity Point Theorems in Multiplicative Metric Spaces by extending the results of [1] and [19] from Metric Space to Multiplicative Metric Space. For the three classes of cyclic mappings mentioned above. The best proximity point theorems were established in the setting of multiplicative metric spaces.

Various classes of mappings introduced in this research can be further studied. It is recommended that, best proximity point should be investigated further in multiplicative metric space. Common best proximity point in multiplicative metric space may also be investigated. It may also be possible to establish fixed point theorem(s) in multiplicative metric spaces using a newly introduced multiplicative cyclic contraction mappings. It is recommended that example(s) of a generalized multiplicative $R$-cyclic contraction mapping which is not a multiplicative $R$-cyclic contraction be constructed.

\section{References}

[1] Eldred, A.A. and Veeramani, P. (2006). Existence and Convergence of Best Proximity Points. MathematicalAnalysis and Application, 323: pp1001-1006.

[2] Bashirov, A.E., Karplnara, E. M., and Ozyaplcl, A.O. (2008). Multiplicative Calculus and its Application. Journal of Mathematical Analysis and Applications, 337:36-48.

[3] Ozavsar, M. and Cervikel, A. C. (2012). Fixed Point of Multiplicative Contraction Mappings on Multiplicative Metric Spaces. arXiv:1205.513lvl[math.GM].

[4] Sarwar, M. and Rome, B. (2014). Some Unique Fixed Point Theorems in Multiplicative Metric Space. arXiv:1410.3384v2[math.GM].

[5] Abbas, M., Ali, B., and Suleiman, Y.I (2015). Common Fixed Points of Locally Contractive Mappings in Multiplicative Metric Space with application. International Journal of Mathematical Science, 2015(Article ID 218683, Doi:10.1155/2015/218683):7 pages.

[6] Du, W. and Lakzian, H. (2012). Nonlinear Conditions for the Existence of Best Proximity Points. Journal of Inequality and Applications, vol. 206:pp. 1-7.

[7] Niyom, S., Boriwan, P., and Petrot, N. (2015). Best Proximity Point Theorem on a Class of Generalized Cyclic Contraction Mapping. Journal of inequalities and Applications, vol. 166: pp. 1-3.

[8] Kirchhoff, D.G. and Kellog (1922). Invariant Points in Function Spaces. Trans of American Mathematical Society, 23: pp96-115. 
A.U Terrang et al. / NIPES Journal of Science and Technology Research

2(2) 2020 pp. $78-89$

[9] Hxiaoju, H., Song, M., and Chen, D. (2014). Common Fixed Points for Weak Commutative Mappings on a Multiplicative Metric Space. Fixed point theory and application, vol. 48: pp. 2-9.

[10] Bashirov, A.E., Misirli, E., Tandogdu, Y., and Ozyaplcl, A. (2011). On Modeling with Multiplicative Differential Equations. Applied Mathematics, 26: pp 425-438.

[11] Florack, L. and Assen, H.V. (2012 ). Multiplicative Calculus in Biomedical Image Analysis. Journal of Mathematical Imaging and Vision, 42(1):pp64-75.

[12]Fan, K. (1969). Extension of Two Fixed Points Theorems of F.E. Browder. Mathematische Zeitsch, 112(3): pp234-240.

[13] Singxi, S. L., Tiwari, B. M. L., and Gupta, V. K. (1980). Common Fixed Points of Commuting Mappings in 2-Metric Spaces and an Application. Mathematical Nachr, (96): pp293-297.

[14] Sastry, K.P.R., Naidu, G. A., Sharma, K. K. M., and Gayatri, I. L. (2010). Common Fixed Point for Compatible Mappings on 2-Metric Spaces. Global Journal of Mathematical Science; Theory and practical, $2(3)$ : pp173-179.

[15] Gu, F., Cui, L.M., and Wu, Y.H. (2003). Some Fixed Point Theorems for New Contractive Type Mappings. Journal of Qiqihar University, 19: pp85-89.

[16] Mustafa, Z. and Sims, B. (2004). Some Remarks Concerning d-Metric Spaces. In proceedings of international conference on fixed point theory and application, pages 13-19. Yakohan publishers Valencia spain.

[17] Agarwal, R.P., El-Gebily, M.A., and Oregan, D. (2008). Generalized Contractions in Partially Ordered Metric Spaces. Applied Analysis, 87:109-116.

[18] Suzuki, T. (2008). A Generalized Banach Contraction Principle that Characterized Metric Completeness. Proceedings of the American Mathematical Society, 136(5): pp.18611869.

[19]Lin, L.-J., Lakzian, H., and Chou, Y. (2012). On Best Proximity Point Theorems for New Cyclic Maps. International Mathematical Forum, 7(37): pp1839-1849. 